\title{
ETNOGRAFI KOMUNIKASI VISUAL PERTUNJUKAN REYOG OBYOGAN PONOROGO
}

\author{
Oki Cahyo Nugroho \\ Eli Purwati \\ Dosen Program Sudi Ilmu Komunikasi \\ Fakultas Ilmu Sosial dan Ilmu Politik, Universitas Muhammadiyah Ponorogo \\ Jalan Budi Utomo No. 10, Ronowijayan, Siman \\ Ponorogo, Jawa Timur \\ No. Hp.: 085236749281, E-mail: okicahyo@gmail.com
}

\begin{abstract}
ABSTRAK
Perkembangan reyog Ponorogo di tengah majunya komunitas budaya global mempunyai cara khusus dan berbeda dalam penyampaian informasi, terutama dalam pertunjukan reyog obyogan yang ada di Kabupaten Ponorogo. Reyog obyogan merupakan sebuah pertunjukan reyog yang seolah-olah tidak mempunyai aturan dalam pertunjukan, tetapi penuh dengan makna yang terkandung di dalamnya dan tersampaikan dengan model komunikasi visual. Komunikasi visual merupakan sebuah rangkaian proses penyampaian kehendak atau maksud tertentu kepada pihak lain dengan penggunaan media penggambaran yang hanya terbaca oleh indera penglihatan. Dalam bidang ilmu antropologi, kajian ilmu tentang komunikasi dikenal dengan komunikasi etnografi, sebuah proses yang dikembangkan dari pola-pola bicara dalam sebuah komunitas. Penelitian ini menggunakan teori komunikasi budaya dalam ranah etnografi yang dikembangkan oleh Dell Hymes, SPEAKING (setting and scene, participant, event, act squence, key, instrumentalities, norms, and genres). Etnografi merupakan sebuah metode dalam menggali informasi yang terkandung dalam sebuah komunitas budaya dan berusaha mengungkapkan sebuah pesan lewat media tari, ekspresi, dan interaksi. Hal inilah yang menjadi sebuah cara berkomunikasi dengan banyak aspek yang saling terkait. Komunikasi visual dalam penelitian ini, sesuai namanya, adalah komunikasi melalui media penglihatan yang terdokumentasikan dengan media fotografi. Melihat paradigma dan perkembangan inilah, fokus dalam penelitan ini adalah melihat lebih jauh dan mendalam bagaimana tandatanda visual berkembang dalam bentuk komunikasi budaya yang hidup dan tumbuh dalam kesenian reyog terutama reyog obyogan di Kabupaten Ponorogo. Melalui metode penelitian kualitatif dengan observasi mendalam dan wawancara diharapkan hasil yang dicapai dapat lebih maksimal dengan temuan-temuan baru yang ada sesuai dengan perkembangan yang ada pada pertunjukan reyog tersebut.
\end{abstract}

Kata kunci: etnografi, komunikasi visual, reyog Ponorogo, budaya

\begin{abstract}
Visual Communication Ethnography of the Performance of Reyog Obyogan Ponorogo. The development of reyog Ponorogo amid the advancement of the global cultural community has a special and different way of delivering information, especially in the reyog obyogan show in Ponorogo Regency. reyog obyogan is a reyog performance that seems to have no rules in the show, but is full of meaning and conveyed with a visual communication model. Visual communication is a series of processes of conveying the will or intention to another party with the use of imaging media that are only read by the sense of sight. In anthropology, the study of communication is known as ethnographic communication, a process developed from speech patterns in a community. This research uses the theory of cultural communication in the ethnographic developed by Dell Hymes, SPEAKING (setting and scene, participant, event, act sequence, key, instrumentalities, norms, and genres). Ethnography is a method of exploring
\end{abstract}


information contained in a cultural community and trying to express a message through the media of dance, expression, and interaction. This has become a way of communicating with many interrelated aspects. Visual communication in this study, as the name implies, is a communication through visual media documented with photographic media. Seeing the paradigm and the development, the focus in this research is to look further and deeper into how visual signs developed in the form of living and growing cultural communication in reyog artistry, especially reyog obyogan in Ponorogo Regency. Using a qualitative research method with in-depth observation and interviews, it is expected that the results achieved can be maximized with new findings which are in accordance with the existing development of the reyog performance.

Keywords: visual communication, ethnography, reyog Ponorogo, culture

\section{PENDAHULUAN}

Kata obyog atau obyogan diartikan dalam kamus bahasa Jawa adalah bebarengan nyambut gawe dengan pengertian yang sama dalam bahasa Indonesia mengerjakan pekerjaan bersama-sama (Kumorohadi, 2004:23-24). Istilah obyog juga disebut dalam buku pedoman sebagai nama untuk salah satu permainan musik sebagai iringan tari barongan atau tabuhan menjelang pentas (Pemkab Ponorogo, 1993). Salah satu motivasi ramainya pertunjukan reyog obyogan adalah adanya interaksi dan komunikasi antara penonton dengan pemain. Interaksi ini dapat berupa sapaan, mengajak menari bersama bahkan memberikan uang atau biasa disebut dengan saweran. Konco reyog adalah sebutan bagi orang-orang yang antusias dan serta ikut menjadi bagian dari sebuah pertunjukan reyog obyogan meskipun bukan bagian resmi dari tim reyog yang sedang bermain.

Bidang ilmu antroplogi, kajian ilmu tentang komunikasi dikenal dengan komunikasi etnografi, sebuah proses yang dikembangkan dari pola-pola bicara dalam sebuah komunitas. Tokoh yang terkenal dan berkontribusi terhadap gaya komunikasi adalah Hymes dengan SPEAKING (setting and scene, participant, event, act squence, key, instrumentalities, norms, and genres). Masih banyak ilmuwan lain yang fokus tentang budaya dalam komunikasi seperti Philipsen (1975), Carbaugh (1990), Katriel (1986), dan Fitch (1998). Mereka telah berkontribusi dalam analisis mendalam tentang budaya dalam perspektif komunikasi yang memberi pandangan lebih dalam serta menawarkan lebih banyak pertanyaan yang siap dicari hipotesisnya (Saville-Troike, 2003).

Komunikasi visual dalam penelitian ini, sesuai namanya, adalah komunikasi melalui media penglihatan yang terdokumentasikan dengan media fotografi. Komunikasi visual merupakan sebuah rangkaian proses penyampaian kehendak atau maksud tertentu kepada pihak lain dengan penggunaan media penggambaran yang hanya terbaca oleh indera penglihatan. Komunikasi visual mengombinasikan seni, lambang, tipografi, gambar, desain grafis, ilustrasi, dan warna dalam penyampaiannya, tetapi dalam penelitian ini hanya terfokus pada bentuk pertunjukan yang terlihat dan terdokumentasi dengan media fotografi sebagai salah satu media komunikasi visual. 


\section{PEMBAHASAN}

\section{Reyog Obyogan}

Pertunjukan reyog obyogan di pedesaan merupakan kesenian yang biasanya diselenggarakan dalam rangka hajatan atau acara desa dengan melibatkan banyak masyarakat di dalamnya seperti bersih desa, acara ulang tahun kemerdekaan, atau acara spesifik yang lain, seperti syukuran kepala desa.

\section{Situasi Komunikasi Visual dalam Reyog Obyogan}

Sebelum Pertunjukan Dimulai

\section{a. Uluk Salam}

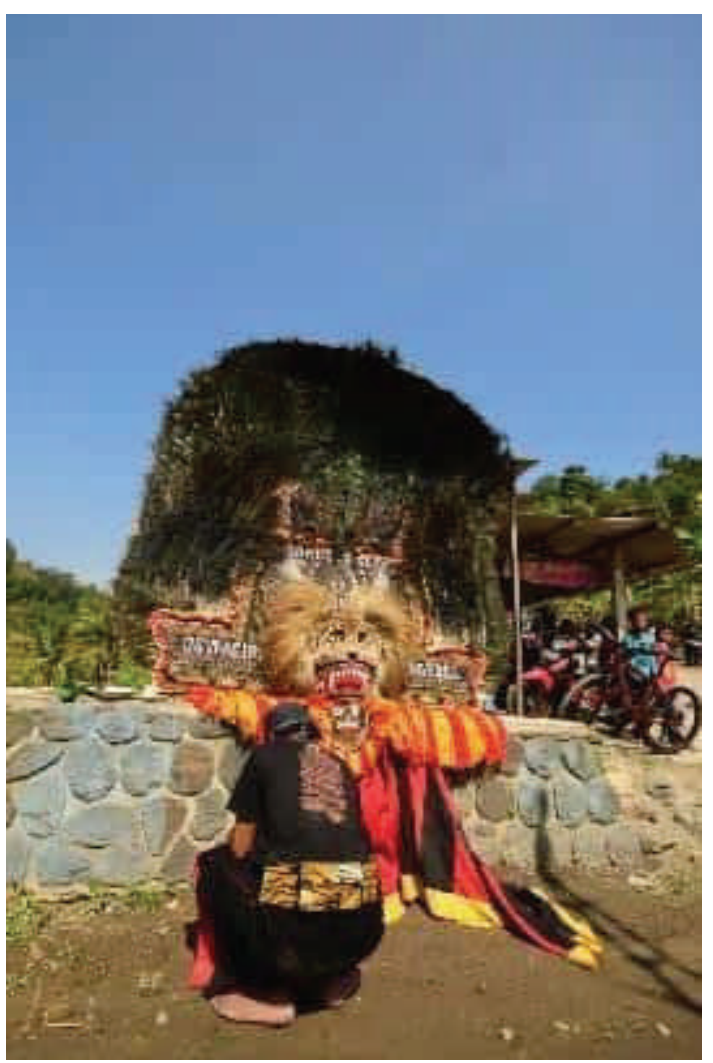

Gambar 1 Bentuk uluk salam sebelum acara pertunjukan reyog obyogan berlangsung di Desa Wager Lor, Ngebel, Ponorogo

\section{b. Tabuhan}

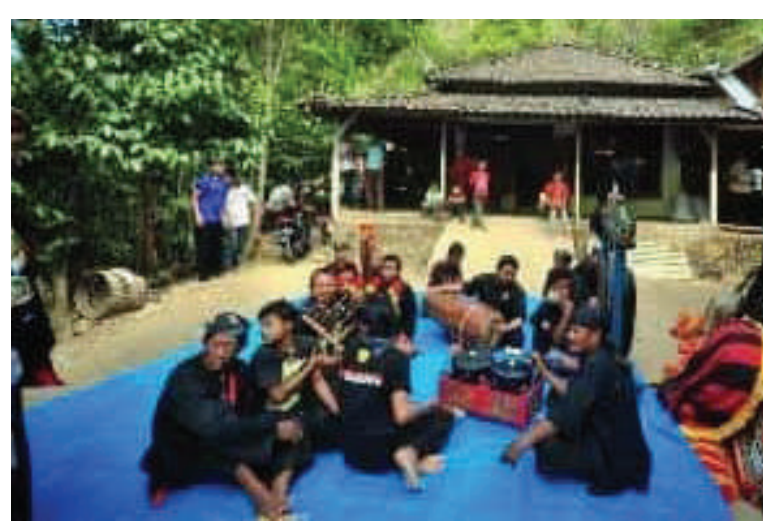

Gambar 2 Tabuhan sebelum pertunjukan reyog obyogan dimulai di Ngilo-Ilo, Slahung, Ponorogo

Tabuhan dalam bahasa Jawa memiliki arti memukul alat musik. Tabuhan dilakukan menjelang pementasan berlangsung. Tabuhan merupakan bentuk komunikasi tradisional dalam rangka mengundang orang sekitar untuk datang menyaksikan pertunjukan reyog ini. Bentuk tabuhan ini bisa bermacam-macam, tetapi yang paling lazim dan peneliti sering jumpai adalah tabuhan tayub atau iring-iring. Beberapa tempat gending atau lagu dalam tabuhan ini adalah kebogiro. Menurut beberapa orang pinisepuh, tabuhan sangat penting peranannya dalam rangka mempersiapkan pertunjukan yang akan berlangsung. Dalam tabuhan ini pula diperiksa kelengkapan, jumlah, dan fungsi masing-masing alat musik berfungsi sebagaimana mestinya. Dalam bahasa yang lazim atau dalam pertunjukan musik modern disebut dengan chek sound. 


\section{Pada Saat Pertunjukan Berlangsung a. Iring-Iring}

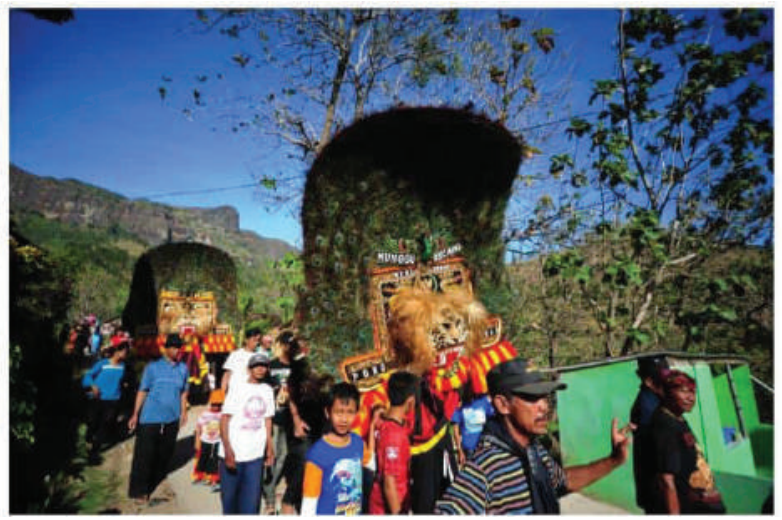

Gambar 3 Bentuk iring-iring reyog obyogan di Munggu, Bungkal, Ponorogo (Foto: Dokumentasi Peneliti)

Konsep iring-iring dalam pertunjukan reyog Ponorogo merupakan bentuk pertunjukan atau pementasan reyog dari satu tempat ke tempat lain. Cara berpindah secara lengkap ini meliputi pemain, perangkat, serta penonton atau yang disebut dengan konco reyog. Konsep iring-iring ini dengan mudah ditemukan dalam pentas reyog obyogan yang diselenggarakan di desa. Hal demikian sangat jarang ditemukan di pentas pertunjukan di kota atau bahkan di daerah mana pun di luar Ponorogo.

Iring-iring merupakan konsep baku dalam sebuah pertunjukan reyog obyogan yang sudah turun-temurun dalam pertunjukan reyog di Ponorogo. Di dalam pertunjukan reyog inilah di samping pertunjukan sebagai sarana hiburan, nilai-nilai dalam kehidupan juga turut diajarkan. Konsep bermain sambil belajar secara sadar atau tidak akan didistribusikan dalam pertunjukan ini.

Reyog dalam bentuk obyogan merupakan bentuk asli dari pertunjukan reyog yang ada di masyarakat. Bentuk atau format tarian dalam reyog obyogan sangat berbeda dengan festival. Format tarian dalam obyogan seolah hadir tanpa pakem yang jelas, sedangkan reyog dalam bentuk festival hadir dengan aturan baku yang tertulis dan disahkan oleh bupati Ponorogo sebagai penanggung jawab acara secara keseluruhan. Akan tetapi, sebenarnya reyog dalam bentuk obyogan mengikuti pakem-pakem reyog yang sudah turun-temurun sejak zaman dahulu.

\section{b. Edreg}

Salah satu ciri khas dalam pertunjukan reyog obyogan adalah adanya satu gerakan tari yang disebut dengan edreg. Edreg merupakan gerakan penari jathil berjalan menyamping mendekati penari dadak merak atau bujangganong (Simatupang, 2013:130).

\section{Edreg penari jathil ke bujangganong}

Gerakan edreg penari jathil terhadap penari bujangganong adalah sebuah peristiwa yang sering terjadi ada setiap pertunjukan yang terjadi dalam pertunjukan reyog obyogan. Penari bujangganong dituntut atraktif dan komunikatif terhadap penonton ataupun terhadap penari-penari yang lain seperti bujangganong atau dadak merak. Biasanya gerakan ini dapat dijumpai ketika penari bujangganong selesai melakukan atraksi dan duduk jongkok dengan bertumpu pada lutut sambil memandang salah satu jathil, maka dengan segera penari jathil akan menghampiri penari bujangganong tersebut dengan gerakan bergoyang menyamping mendekati penari bujangganong.

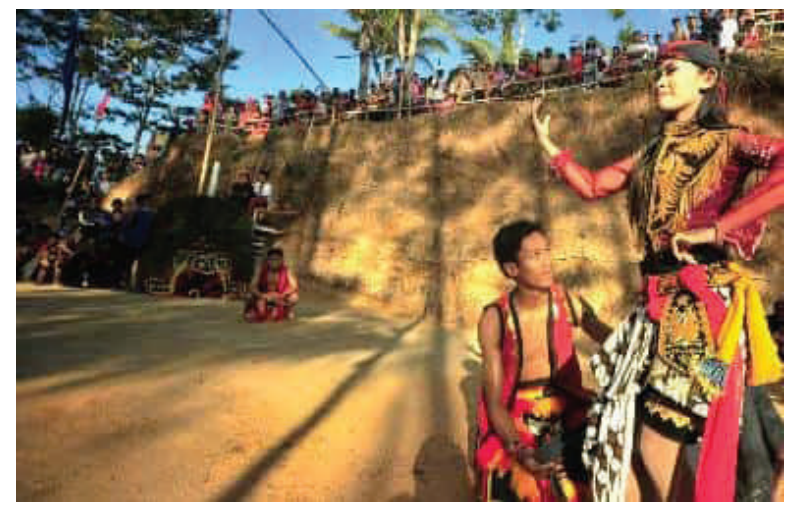

Gambar 4 Edreg penari jathil dalam bujangganong (Foto: Dokumentasi Peneliti) 


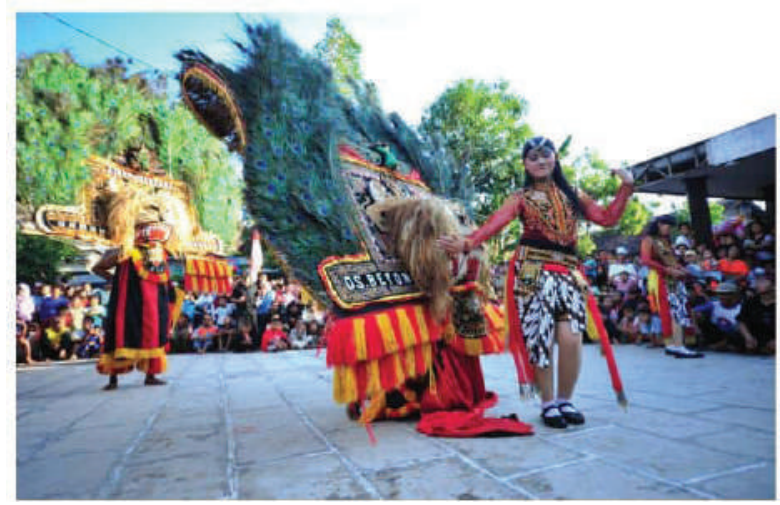

Gambar 5 Edreg penari jathil ke dadak merak (Foto: Dokumentasi Peneliti)

\section{Edreg penari jathil ke dadak merak}

Salah satunya adalah gerakan edreg dari penari jathil ke dadak merak. Hal ini akan ditemui hampir di setiap pertunjukan reyog obyogan di Ponorogo. Gerakan ini dapat dilihat setelah dadak merak atau kadang disebut panjak barong melakukan atraksi dengan mengibaskan dadak meraknya ke segala arah, berguling, melompat, dan seperti menerkam mangsa. Setelah itu, dadak merak akan duduk jongkok dengan memandang salah satu penari jathil. Kemudian penari jathil akan melakukan gerakan menari menyamping sambil mendekat ke arah dadak merak tersebut.

\section{Edreg penari jathil ke konco reyog}

Salah satu keunikan lain yang hanya ada dan dapat ditemui dalam pertunjukan reyog obyog adalah adanya edreg dari penari jathil kepada konco reyog. Hal ini dapat terjadi karena adanya interaksi dan keterbukaan dalam pertunjukan reyog obyogan. Hal ini tidak mungkin dapat ditemui dalam pertunjukan reyog dengan format festival. Adanya interaksi yang bersifat terbuka antara pemain dan konco reyog membuat pertunjukan reyog di mana pun berada akan menjadi tontonan yang selalu dinanti dan ramai oleh penonton.

\section{c. Gebyagan}

Pertunjukan reyog terutama obyogan sangat kental dengan nuansa status sosial dalam pemilihan tempat pementasannya. Dalam sebuah pementasan, awal dari pertunjukan reyog berawal dari orang-orang yang mempunyai pengaruh di daerah setempat. Sebagai contoh lurah atau kepala desa yang menjadi tempat awal atau pemberangkatan dari pertunjukan reyog tersebut. Dalam proses perjalanan ke tempat selanjutnya, grup reyog ini akan berhenti di rumah-rumah warga yang dianggap mempunyai pengaruh masyarakat desa setempat. Pengaruh-pengaruh dalam masyarakat desa ini dapat beragam bentuknya, dari pengaruh dalam bidang politik, sosial, pendidikan, atau keagamaan. Grup reyog ini akan berhenti dan iker atau melakukan pertunjukan singkat di depan rumah tersebut. Merupakan suatu kehormatan tersendiri bagi warga setempat yang halaman rumahnya menjadi tempat pertunjukan reyog dan didatangi banyak orang atau mampir ke rumahnya.

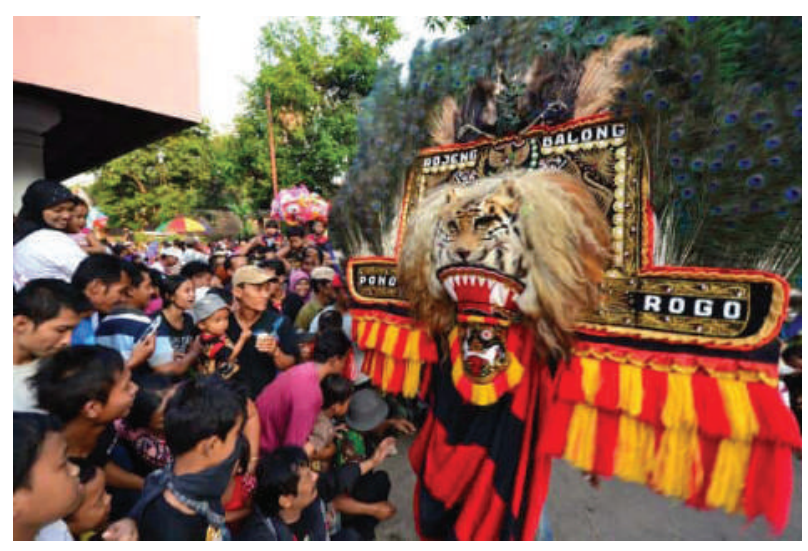

Gambar 8 Kibasan pertama dalam reyog obyogan sebagai simbol menghilangkan hawa negatif dalam pertunjukan (Foto: Dokumentasi Peneliti) 
Gebyakan mempunyai beberapa fungsi dalam pertunjukan reyog obyogan. Gebyakan dapat diartikan sebagai pengusir hawa jahat atau sifat negatif kepada konco reyog sebelum pertunjukan dimulai. Gebyakan pertama biasanya akan dimulai dengan dadak merak yang maju ke tengah arena dan mengibaskan dadak merak ke arah penonton sampai hampir menyentuhnya. Fungsi yang kedua selain sebagai pengusir sifat negatif, gebyakan juga berfungsi sebagai sarana membuka arena untuk pertunjukan.

d. Peristiwa komunikasi visual dalam reyog obyogan

Peristiwa komunikatif terutama dalam bentuk visual merupakan sebuah perangkat atau komponen yang utuh dimulai dari tujuan komunikasi, topik umum yang sama, dan melibatkan partisipan yang secara umum komunikasi, topik umum yang sama, melibatkan masyarakat dengan varietas bahasa yang sama, mempertahankan tone yang sama, dan kaidahkaidah yang sama dalam interaksi, dalam setting yang sama. Sebuah peristiwa komunikatif dinyatakan berakhir ketika terjadi perubahan partisipan, adanya periode hening, atau perubahan posisi tubuh (Kuswarno, 2009:41).

\section{Tipe Peristiwa (Genre)}

Menurut beberapa tokoh tua atau sesepuh dari reyog Ponorogo, reyog merupakan sebuah pertunjukan yang digunakan sebagai acara perayaan sesuatu di sebuah daerah. Reyog juga digunakan oleh beberapa kelompok masyarakat untuk mengumpulkan balung pisah atau sebagai media komunikasi sosial dalam sebuah ikatan tertentu. Pertunjukan reyog juga mempunyai fungsi menguatkan ikatan persaudaraan antarwarga dengan cara bekerja secara bersama-sama dengan kemampuan yang dimiliki. Artinya bentuk pertunjukan ini merupakan sebuah bentuk lain dari gotong royong warga masyarakat setempat.

\section{Topik}

Reyog dalam bentuk obyogan merupakan bentuk asli dari pertunjukan reyog yang ada di masyarakat. Bentuk atau format tarian dalam reyog obyogan sangat berbeda dengan festival. Format tarian dalam obyogan seolah hadir tanpa pakem yang jelas, sedangkan reyog dalam bentuk festival hadir dengan aturan baku yang tertulis dan disahkan oleh Bupati Ponorogo sebagai penanggung jawab acara secara keseluruhan. Akan tetapi, sebenarnya reyog dalam bentuk obyogan mengikuti pakempakem reyog yang sudah turun-temurun sejak zaman dahulu.

\section{Fungsi dan Tujuan}

Menurut beberapa tokoh tua atau sesepuh dari reyog Ponorogo sendiri, reyog merupakan sebuah pertunjukan yang digunakan sebagai acara perayaan sesuatu di sebuah daerah. Reyog juga digunakan oleh beberapa kelompok masyarakat untuk mengumpulkan balung pisah atau sebagai media komunikasi sosial dalam sebuah ikatan tertentu. Pertunjukan reyog juga mempunyai fungsi menguatkan ikatan persaudaraan antarwarga dengan cara bekerja secara bersama-sama dengan kemampuan yang dimiliki. Artinya bentuk pertunjukan ini merupakan sebuah bentuk lain dari gotong royong warga masyarakat setempat. 


\section{Setting}

Reyog ini mempunyai sebuah ciri khas meminimalisasi atau sangat sedikit dalam mengubah alam untuk mencapai suatu tujuan. Jika dihubungkan dengan pertunjukan reyog yang ada di Ponorogo, reyog dalam bentuk obyogan sangat harmonis dengan alam. Hal ini dibuktikan dengan bentuk pementasan reyog obyogan tidak menggunakan panggung seperti dalam reyog festival. Reyog dalam bentuk obyogan juga tidak menggunakan perangkat pengeras suara, tetapi menggunakan kekuatan suara dari gamelan tersebut. Reyog obyogan juga tidak menggunakan tata cahaya dalam membantu penerangan selama pementasan atau hanya mengandalkan penerangan cahaya matahari atau available light seadanya.

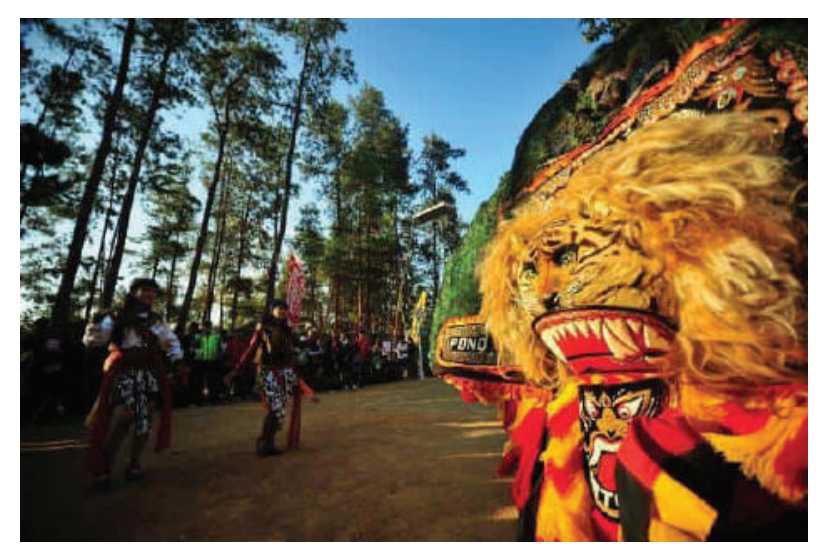

Gambar 9 Panggung alam dalam pertunjukan reyog obyogan

5. Partisipan

Penari dalam reyog obyogan tidak selengkap dalam pementasan reyog festival. Dalam pertunjukan reyogobyogan, jumlah penari dapat bervariatif tergantung dari kekuatan lembaga atau pihak penyelenggara dalam konektivitas atau hubungan sosial dengan kelompok reyog yang lain. Kekuatan dalam pendanaan juga memengaruhi jumlah pemain obyogan. Dalam pementasan reyog obyogan, pakem atau pemain bakunya adalah dadak merak, jathil, dan bujangganong. Ketiga pemain inilah yang menjadi pemain inti dalam pertunjukan reyog obyogan. Peran penari warok dan Prabu Klanasewandana seolah dilupakan.

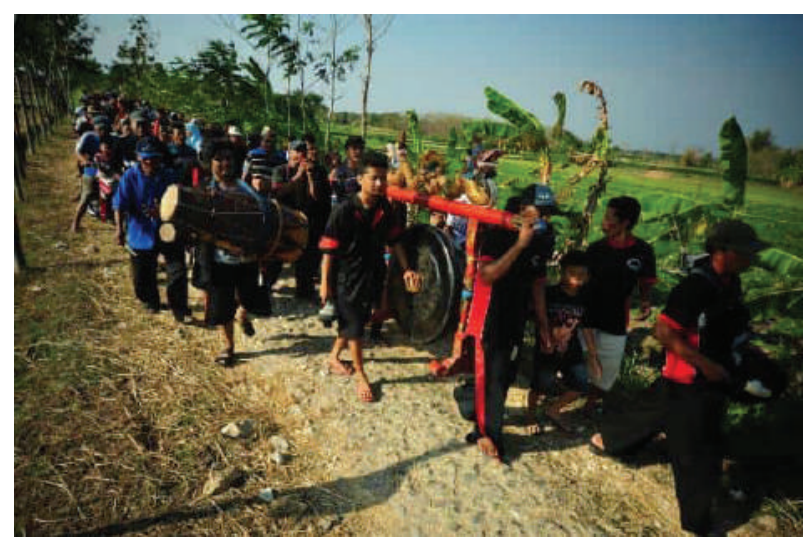

Gambar 10 Partisipan atau konco reyog dalam pertunjukan reyog obyogan

\section{Ends}

Secara langsung pertunjukan reyog merupakan sebuah media silaturahmi dan komunikasi antarwarga secara gratis. Hal ini dimungkinkan karena pertunjukan reyog dengan format obyogan diselenggarakan di ruang terbuka umum yang mudah diakses oleh warga masyarakat. Pertunjukan yang diselenggarakan secara terbuka secara langsung akan menarik perhatian warga untuk berkumpul.

$$
\text { Pertunjukan reyog obyogan }
$$
yang berada di ruang terbuka publik memungkinkan antarindividu bisa leluasa memilih tempat untuk menonton. Kontak fisik dan komunikasi dengan masyarakat lain secara langsung sangat dimungkinkan dengan cara seperti ini. Dekatnya individu satu dengan individu yang lain 
dan bisa bertatap muka secara langsung memungkinkan percakapan secara langsung dan spontan.

\section{Bentuk Pesan}

Inlow-contextcultures, information sharing is explicit and direct, whereas in high-context cultues, information saring is implicit and indirect (Hall, 2004). Hal ini sesuai dengan fenomena yang terjadi dalam pertunjukan reyog. Reyog dengan kategori obyogan merupakan reyog dengan cara penyampaian pesan yang tidak langsung dan cenderung pesan tersirat dalam tindakan. Sementara itu, reyog dalam kategori festival merupakan reyog dengan pola penyampaian pesan yang tegas, langsung, dan mudah dipahami.

Reyog dalam bentuk obyogan masuk dalam kategori high culture context karena bentuk penyampaian pesan yang tidak langsung. Pesan-pesan yang tidak langsung ini terkandung dalam tindakantindakan komunikatif selama pertunjukan berlangsung. Pesan-pesan yang ada merupakan bentuk pesan yang lebih banyak menekankan aspek nonverbal di dalamnya.

Reyog dalam bentuk obyogan merupakan bentuk pertunjukan dengan pola penyampaian pesan yang sangat unik dibanding dengan pertunjukan-pertunjukan lainnya. Pertunjukan ini menyampaikan pesannya tidak hanya dengan gerakan, tetapi lebih kompleks lagi, yaitu dengan pakaian atau tindakan.

Bentuk-bentuk tindakan komunikatif inilah yang menarik dan berbeda dari pertunjukan reyog dalam bentuk festival yang semua aspek pertunjukannya sudah ditata sedemikian rupa sehingga orang yang melihat dapat dengan mudah memahami maksud dan tujuan dalam pertunjukan reyog festival.

Bentuk-bentuk pesan yang disampaikan secara tidak langsung dalam pertunjukan reyog ini dapat terjadi dalam beberapa bentuk. Hal yang paling sering terlihat adalah adanya pesan yang membingungkan dari penari jathil dalam pertunjukan reyog obyogan.

8. Isyarat dalam Bentuk Komunikasi Visual a. Saweran

Pertunjukan reyog obyogan terkadang mempunyai sebuah bentuk pertunjukan yang unik. Bentuk pertunjukan ini adalah kesenian rakyat yang pemain dan penontonnya bisa berbaur menjadi satu. Bentuk dari keunikan ini adalah saweran. Salah satu motivasi ramainya pertunjukan reyog obyogan adalah adanya interaksi dan komunikasi antara penonton dan pemain. Interaksi ini dapat berupa sapaan, mengajak menari bersama, bahkan memberikan uang atau biasa disebut dengan saweran. Konco reyog adalah sebutan bagi orang-orang yang antusias dan serta ikut menjadi bagian dari sebuah pertunjukan reyog obyogan meskipun bukan bagian resmi dari tim reyog yang sedang bermain.

Saweran dalam reyog obyogan sebenarnya tidak terlalu lazim atau dapat ditemui di setiap pementasan reyog dalam bentuk obyogan. Saweran ini hanya ada di daerah-daerah tertentu dengan loyalitas konco reyog yang cukup tinggi terhadap grup reyog tersebut atau 
adanya ikatan batin dengan grup reyog tersebut. Dengan demikian, saweran ini pun tidak bisa ditemui dalam setiap pertunjukan reyog obyogan. Peristiwa ini hanya dapat dijumpai dalam pertunjukan reyog obyogan terutama di daerah timur Ponorogo, di antaranya adalah daerah Ngebel, Sambit, dan Sawoo.

\section{b. Iring-Iring}

Perpindahan ini merupakan bentuk komunikasi yang unik dengan banyak mengandung pesan di dalamnya. Dengan demikian, gaya yang ditampilkan dalam prosesi iring-iring ini adalah gaya komunikasi secara tidak langsung dengan menggunakan simbol-simbol tertentu. Masyarakat yang hadir di sana sebagai konco reyog juga tidak perlu diajak untuk mengiringi karena informasi seperti ini sudah ada di dalam kepala konco reyog bahwa pertunjukan reyog obyogan seperti ini akan berpindah dan iker dari satu tempat ke tempat lain.

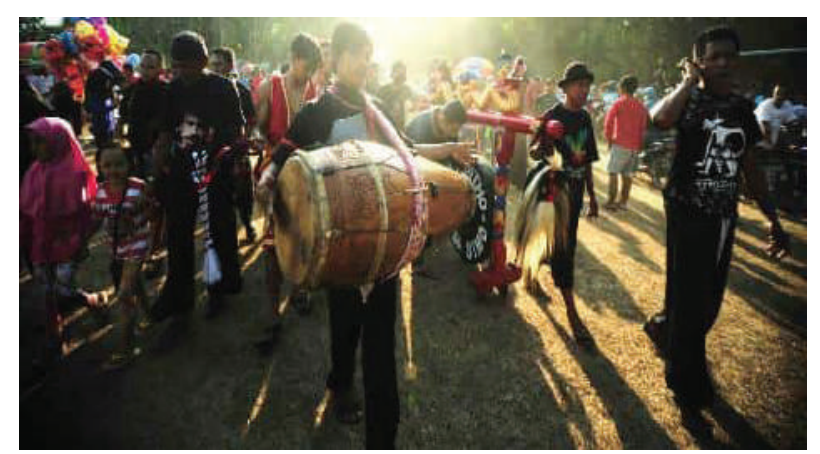

Gambar 12 Modifikasi pada perangkat pertunjukan pada kendang dan kempul (Foto: Dokumentasi Peneliti)

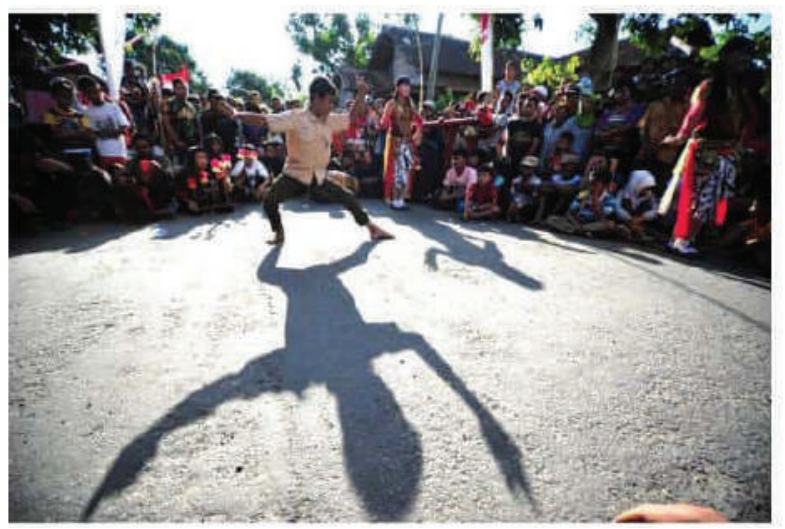

Gambar 13 Yusuf menari bujangganong dengan pakaian seragam Pramuka dalam pertunjukan reyog obyogan di Turi, Jetis, Ponorogo (Foto: Dokumentasi Peneliti)

\section{c . Ikut menari dalam pertunjukan}

Kondisi ini merupakan kondisi yang lazim atau wajar dan dapat ditemui hampir di seluruh pertunjukan reyog obyogan. Dalam pertunjukan reyog obyogan, peran yang sering digantikan dengan pemain lain atau konco reyog yang lain adalah bujangganong dan barongan atau dadak merak. Peran-peran inilah yang dapat digantikan oleh konco reyog karena tidak adanya sekat antara pemain dan penontonnya. Hal ini merupakan bentuk yang berbeda jika dibandingkan dengan pertunjukan reyog festival karena perannya tidak dapat digantikan oleh orang lain apalagi tanpa kostum atau pakaian untuk menari dalam pertunjukan tersebut.

9. Act Sequence (Isi Pesan atau Urutan Tindak)

\section{a. Gotong royong}

Pertunjukan reyog obyogan penuh dengan sikap gotong royong dan kebersamaan. Sikap gotong royong ini merupakan sikap atau perilaku yang khas orang-orang desa yang biasanya hidup dalam sistem mata pencaharian agraris 
atau pertanian. Sikap gotong royong ini terlihat dari bentuk iring-iringan dalam pementasan obyogan dari satu tempat ketempat lain. Tidak hanya itu, sikap gotong royong terlihat dalam bentuk aktivitas seperti persiapan konsumsi, kepanitiaan, serta tempat singgah yang semuanya adalah murni dukungan warga yang suka rela menyumbangkannya agar pertunjukan ini berjalan dengan lancar.

Sikap gotong royong inilah yang menyebabkan tidak ada sifat kompetisi dalam pementasannya. Sikap-sikap inilah yang menjadi pembeda antara reyog festival dan reyog obyogan. Hal ini juga memengaruhi cara bersikap dalam berkomunikasi dalam menjalankan seluruh aktivitas baik dalam reyog obyogan ataupun dalam reyog festival.

Reyog dalam bentuk obyogan merupakan sebuah kesenian rakyat yang seluruh elemen masyarakatnya mempunyai peran dalam pementasannya. Pada sebagian besar pertunjukan reyog obyogan diselenggarakan oleh pemerintah desa atau kelompok masyarakat di pedesaan. Oleh karena itu, seluruh warga ikut berperan serta dengan dukungan dana yang terbatas. Terkadang warga turut menyumbang dengan suka rela dalam bentuk tenaga atau beberapa kebutuhan yang dirasakan perlu.

\section{b. Egaliter atau sama derajat}

Reyog dengan format obyogan dengan cara pertunjukan yang tidak ada batas antara konco reyog satu dengan konco reyog yang lain membuat proses komunikasi dan intrekasi berjalan tanpa hambatan. Dengan demikian, tidak ada batas hierarki dalam bentuk status sosial yang tampak dalam pertunjukan reyog obyogan. Hal ini dapat dibuktikan dengan berbaur dan menyatunya semua elemen masyarakat baik itu pejabat pemerintahan, kepala desa, lurah, pamong sampai ke rakyat biasa dalam satu arena tanpa batas dan sekat. Bentuk sikap egalitarian ini merupakan perwujudan nyata dari persamaan derajat antara rakyat biasa dan orang yang berpangkat atau mempunyai kedudukan lebih tinggi dalam masyarakat khususya dalam bidang pemerintahan.

Konco reyog memegang peranan penting dalam pembentukan sikap dalam persamaan derajat ini. Beberapa faktor yang memengaruhinya antara lain adalah faktor pengetahuan dan intelektualitas konco reyog itu sendiri. Artinya, sebagian besar konco reyog yang hadir dalam kalangan ini adalah para petani dengan tingkat intelektual terbatas sehingga mereka juga jarang yang menjabat atau mempunyai pengaruh kuat dalam pemeritahan. Maka, dari sisi inilah seakan-akan semua konco reyog yang hadir dalam pertunjukan ini merasa sama, baik yang berpangkat atau mempunyai kedudukan di pemerinahan atau rakyat biasa.

Faktor lain yang memengaruhi pembentukan sikap egaliter ini adalah faktor lingkungan pertunjukan. Reyog obyogan merupakan konsep kesenian dengan memanfaatkan lingkungan sekitar dengan sedikit modifikasi alam dalam pertunjukannya. Hal ini dapat dilihat dari bentuk pertunjukannya yang berada di tempat-tempat umum seperti 
lapangan, jalan, halaman rumah, atau tempat umum lainnya. Dengan demikian, tidak ada pembuatan panggung dan penataan tempat duduk sesuai dengan kepentingan penonton. Dalam hal ini, siapa yang datang lebih dulu maka bisa melihat pertunjukan dari posisi yang paling depan.

\section{Kaidah Interaksi}

a. Tidak ada kelas penonton

Sifat egaliter dalam pertunjukan reyog obyogan ditunjukkan dengan bentuk tidak adanya kelas dalam penonton atau konco reyog tersebut. Sebagai bentuk dari persamaan kelas dalam melihat pertunjukan ini adalah tidak adanya kursi atau sekat khusus yang membedakan antara penonton dengan kelas sosial tinggi atau penonton dalam status sosial sedang atau rendah. Dalam pertunjukan inilah semua orang dengan beragam status sosial dapat berkumpul, berinteraksi, dan berkomunikasi tanpa batas, dan secara langsung.

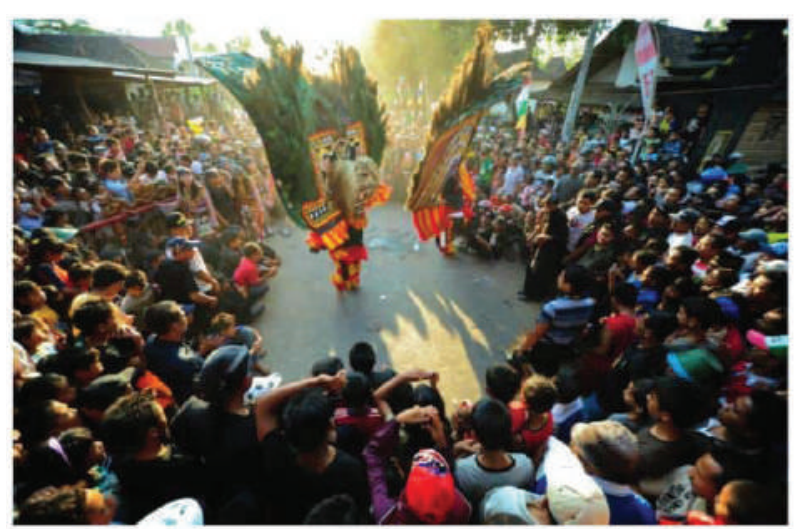

Gambar 14 Semua penonton atau konco reyog menjadi satu dalam melihat reyog obyoan di Tegalombo, Kauman, Ponorogo (Foto: Dokumentasi Peneliti)

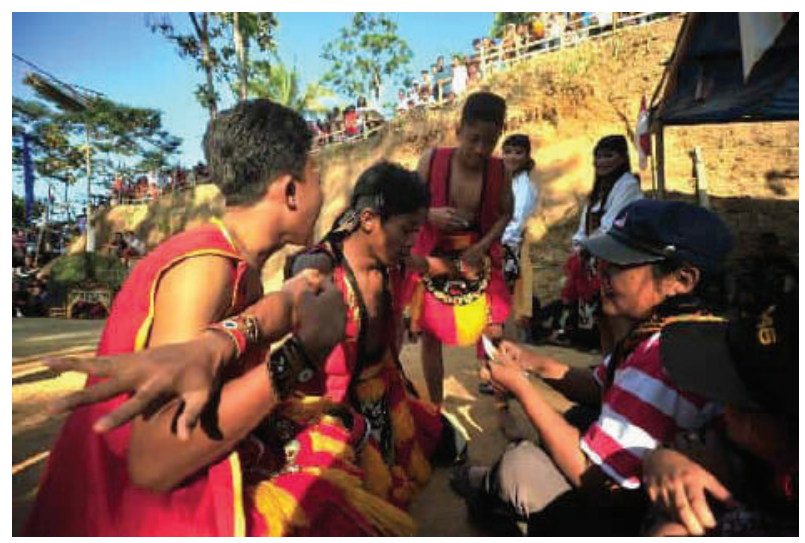

Gambar 15 Bentuk interaksi dengan konco reyog dalam pertunjukan reyog obyogan di Desa Ngilo-Ilo

(Foto: Dokumentasi Peneliti)

\section{b. Bercanda dengan konco reyog}

Dalam seluruh rangkaian pertunjukan ini hanya penonton yang menjadi pusat perhatian dari interaksi yang terjadi. Akan tetapi, interaksi ini bukanlah tanpa aturan. Aturan tidak tertulis dalam pertunjukan merupakan bentuk dari penghormatan dan kedekatan antara satu pemain dan pemain lain dan dengan konco reyog yang lain. Ternyata interaksi ini merupakan sebuah wujud penghormatan tertinggi kepada tokoh masyarakat setempat karena seseorang yang didatangi merupakan tokoh atau orang yang berpengaruh di lingkungan itu atau masyarakat sekitar. Dalam pertunjukan ini yang dimaksud adalah Kepala Desa Ngilo-Ilo yang menjadi motor penggerak dari acara pertunjukan reyog yang baru kali pertama diadakan di daerah terpencil ini.

\section{Norma Intepretasi}

Reyog dalam bentuk obyogan masih bertahan dengan tradisi turuntemurun yang diwariskan dari generasi sebelumnya. Dalam pertunjukan ini hal yang memengaruhi pertunjukan 
lebih bersifat sosial di antaranya adalah semangat gotong royong, kekeluargaan, dan solidaritas kelompok. Makna yang disampaikan dalam reyog sama, yaitu kisah perjuangan Prabu Klanasewandana dalam melamar Dewi Songgolangit.

Secara sederhana, titik temu dalam kedua pertunjukan ini adalah sama, yaitu adanya semangat dalam perjuangan romantisme Prabu Klanasewandna dalam usahanya melamar Dewi Songgolangit. Identitas yang dibangun dalam pertunjukan ini juga sama, yaitu sebuah pertunjukan reyog yang tidak bisa berdiri sendiri dalam pementasannya. Artinya personel yang bermain dalam pertunjukan reyog tidak bisa bermain secara individu, tetapi harus bermain dalam sebuah kelompok pertunjukan reyog itu sendiri. Kesamaan lain adalah kostum dan tokoh dalam pertunjukan ini yang tidak mengalami perbedaan baik dalam reyog obyogan maupun festival.

Dalam teori yang dikemukakan oleh Edward Hall, budaya dengan high culture context memegang sistem hierarki yang ketat dalam kehidupan sehari-hari. Sistem ini menjamin adanya informasi yang bersifat tertutup terhadap orientasi kelompok tertentu. Akan tetapi, hal ini tidak berlaku dalam penonton atau konco reyog dalam melihat pertunjukan reyog obyogan yang ada di Ponorogo. Sikap egaliter dengan mengesampingkan status sosial bisa dirasakan dan amati dalam setiap pertunjukan. High culture context dalam sikap egaliter merupakan hal yang bertolak belakang dalam beberapa kajian yang dikemukakan dalam beberapa buku dan kajian.
Tindakan Komunikasi Visual dalam Reyog Obyogan

\section{Saweran}

Seperti yang sudah dijelaskan dalam peristiwa komunikasi di atas, saweran tidak terlalu lazim dalam pertunjukan reyog Ponorogo, terutama reyog obyogan. Akan tetapi, beberapa tempat kadang melakukan hal tersebut. Saweran ini hanya ada di daerahdaerah tertentu dengan loyalitas konco reyog yang cukup tinggi terhadap grup reyog tersebut atau adanya ikatan batin dengan grup reyog tersebut. Dengan demikian, saweran ini pun tidak bisa ditemui dalam setiap pertunjukan reyog obyogan. Peristiwa ini hanya dapat dijumpai dalam pertunjukan reyog obyogan terutama di daerah timur Ponorogo, di antaranya adalah daerah Ngebel, Sambit, dan Sawoo.

\section{b. Iring-Iring}

Ada dua versi latar belakang peristiwa lamaran ini, yang pertama versi hadiah atau sayembara dari Raja Kediri yang sebagai hadiah dari keberhasilan Klana Sewandana mengatasi musibah di Kerajaan Kediri. Versi yang lain merupakan kisah jatuh cinta Prabu Klanasewandana kepada Dewi Songgolangit yang terkenal akan kecantikannya. Peristiwa ini adalah kesimpulan yang mengandung sebuah pesan bahwa dalam sebuah tarian reyog merupakan sebuah pengorbanan demi cinta seseorang. Pesan yang lain dari mitos ini adalah kerja keras yang ditunjukkan oleh Klanasewandana dengan mengatasi pagebluk dan berusaha memenuhi keinginan dari Dewi Songgolangit. 


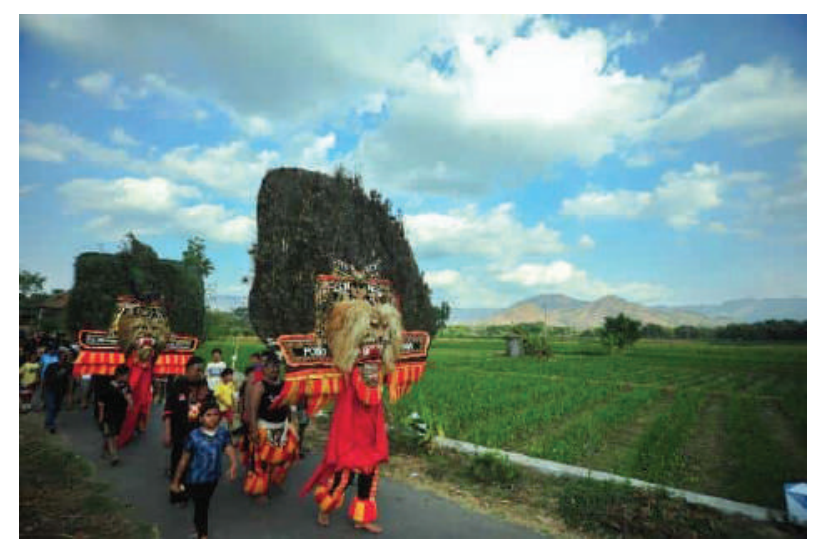

Gambar 17 Peristiwa iring-iring yang diikuti oleh warga masyarakat

\section{c. Edreg}

Salah satu ciri khas dalam pertunjukan reyog obyogan adalah adanya satu gerakan tari yang disebut dengan edreg. Edreg merupakan gerakan penari jathil berjalan menyamping mendekati penari dadak merak atau bujangganong (Simatupang, 2013:130).

Gerakan tari dengan ciri khas menggoda dan terkadang agak seronok ini hanya terjadi dalam pementasan reyog obyogan. Gerakan ini muncul setelah dadak merak "mengamuk" atau unjuk kebolehan di depan para konco reyog. Edreg ini hanya dapat ditemui dalam pementasan reyog obyogan. Dalam pertunjukan reyog obyogan, tidak hanya penari dadak merak yang terbuai oleh penari jathil, tetapi terkadang penari bujangganong juga terbuai akan goyangan dari penari jathil ini.

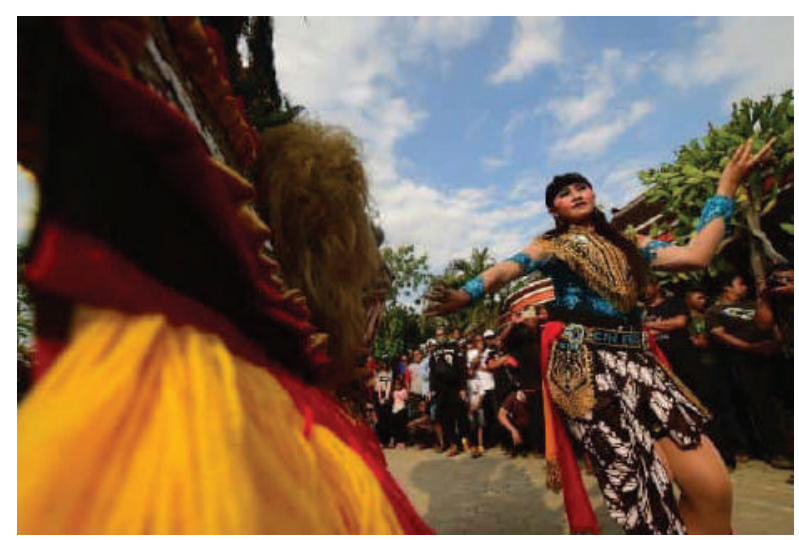

Gambar 18 Edreg jathil ke dadak merak

\section{SIMPULAN}

\section{Komunikasi Visual Berlangsung Sebelum dan pada Saat Pertunjukan Berlangung}

Dalam hal sosial kemasyarakatan dan organisasi sosial, pertunjukan reyog Ponorogo juga dipengaruhi oleh budaya Ponoragan yang mementingkan aspek warok dalam pertunjukannya. Akan tetapi, hal ini sudah berbeda dalam kenyataan di lapangan. Warok dalam organisasi sosial Ponorogo dianggap mempunyai peranan penting sebagai publik figur.

Sistem pengetahuan dalam budaya Ponoragan telah berkembang. Sebagai bukti adalah perkembangan pengetahuan dalam budaya Ponoragan dalam pertunjukan reyog, baik dalam reyog obyogan maupun reyog festival. Sistem pengetahuan ini memengaruhi bentuk komunikasi visual dalam pertunjukan reyog obyogan.

Bentuk komunikasi visual yang ada dalam pertunjukan reyog obyogan sebelum pertunjukan dimulai sangatlah kental dengan nuansa mistik dan kejawen. Nuansa ini tidak serta merta menjadi satu tujuan utama atau seragam dalam setiap pertunjukan reyog yang ada di Ponorogo. Hanya beberapa grup yang masih meyakini hal tersebut. Grup reyog dengan kepercayaan kejawen memang masih 
menjadi rujukan terutama dalam memegang pakem tarian, makna pesan, atau norma dalam pertunjukan. Akan tetapi, hal tersebut mulai bergeser seiring dengan pengetahuan tentang agama yang semakin tinggi dan pengetauan dalam ranah akademik yang semakin mudah didapat oleh setiap personelnya.

\section{Komunikasi Visual Mempunyai Banyak \\ Makna dan Perlu Pemahaman Budaya}

Tersendiri untuk Dapat Memaknai Secara

\section{Komprehensif}

Pertunjukan reyog terutama dalam bentuk obyogan merupakan sebuah pertunjukan unik dari berbagai aspek, terutama dalam aspek visual. Aspek visual ini memegang peranan yang unik karena setelah aspek audio yang dimainkan, konco reyog akan fokus ke arah visual image yang tampil di hadapan mereka. Tampilan-tamplan visual dalam pertunjukan reyog sangat memengaruhi pertunjukan reyog dan mempunyai karakter yang unik antara satu pertunjukan reyog dan pertunjukan reyog yang lain. Sebagai contoh gerakan dadakmerak dalam reyog obyogan antara daerah Ponorogo Timur (Ngebel, Pulung, Sooko, Sawoo) mempunyai karakter yang rancak, cepat, dan dinamis. Akan tetapi, reyog yang berasal dari daerah barat Ponorogo (Ponorogo Kota, Sukorejo, Somoroto, Badegan) mempunyai karakter yang cenderung santai dan kalem. Setelah diamati dan dianalisis dengan berbagai instrumen, didapat simpulan bahwa yang memengarui cara menyampaikan pesan lewat media komunikasi visual dikarenakan situasi dan kondisi dari daerah masing-masing. Artinya reyog dari timur kota Ponorogo akan cepat dan dinamis karena masyarakatnya yang mayoritas adalah masyarakat pegunungan yang menuntut kerja cepat dan dinamis. Berbeda dengan masyarakat dari Ponorogo barat yang dipengaruhi alamnya yang landai dan air melimpah.

\section{KEPUSTAKAAN}

Aryati, L. (2010). Menjadi MC Acara Pernikahan. Jakarta: Gramedia Pustaka Utama.

Aurora, I. (2009, August 12). Photography Basics: Photography as Communication. Diambil kembali dari Photography Basics - photography as communication: https://icelandaurora. com/photo-tutorials/2009/08/ photography-basics-photography-ascommunication/

Ballenger, H. B. (2014). "Photography: A Communication Tool". Art and Design Theses, 7.

Bruce David Forbes, J. H. (2005). Religion and Popular Culture in America. California: University California Press.

Bungin, B. (2008). Penelitian Kualitatif. Jakarta: Kencana.

Communication, I. (2016, 5 23). Interpersonal Communication. Dipetik 5 23, 2016, dari http://www.inc.com/encyclopedia/ interpersonal-communication.html

Dinas Pariwisata dan Seni Budaya, Pemerintah Kabupaten Ponorogo. (1990). Babad Ponorogo Jilid VII. Ponorogo: Dinas Pariwisata dan Seni Budaya.

E.Wileman, R. (1993). Visual Communicating. New Jersey: Educational Technology Pubications.

Fetterman, D. M. (2010). Ethnogrphy: Step by Step.Third Edition. London: Sage Publication Ltd.

Hall, E. (2004). "Beyond Culture". Dalam M. J. Gelfand, \& J. Breet, The Handbook of Negotiation and Culture (hal. 162). Standford, California: Standford University Press.

Hardjana, A. M. (2003). Komunikasi Interpersonal dan Intrapersonal. Yogyakarta: Kanisius.

Iman, N., Kurnianto, R., Harsono, J., \& Santoso, S. (2018). Obyog, Garapan, Pelajar, Santri: 4 Varian Pelestari Seni Reyog Ponorogo. Yogyakarta: Buku Litera Yogyakarta. 
Jazuli. (1994). Telaah Teoretis Seni Tari. Semarang: IKIP Semarang Press.

Katie Milestone, A. M. (2012). Gender and Popular Culture. Cambridge: Polity Press.

Khanfar, Y. (2013). "The Language of Light". World Literature Today, 87, 28.

Kumorohadi, T. (2004). Reyog Obyogan Perubahan dan Keberlanjutan Cara Penyajian dalam Pertunjukan Reyog Ponorogo. Surakarta: PPS STSI.

Kuswarno, E. (2009). Metodologi Penelitian Komunikasi, Fenomenologi, Konsepsi, Pedoman, dan Contoh Penelitiannya. Bandung: Widya Padjajaran.

Lesmana, T. (2009). Dari Soekarno Sampai SBY: Intrik dan Lobi Politik Para Pengusaha. Jakarta: Gramedia Pustaka Utama.

Littlejohn, S. W., \& Foss, K. A. (2009). Encyclopedia of Communication Theory. London: SAGE Publications Ltd.

Littlejohn, W. S., \& Foss, K. A. (2008). Theories of Human Communication. Ninth Edition. Belmont: Thomson Wadsworth.

Management, B. (2016, May 20). Boundless. Differences in Status. Boundless Management. Dipetik may 24, 2016, dari https://www.boundless. com/management/textbooks / boundless-management-textbook/ communication-11/barriers-toeffective-communication-84/ differences-in-status-404-1506/

Martono, H. (2012, Mei). "Reyog dalam Profesi”. Jurnal Tari “Joged”, 3(1), 94.

Moleong, L. J. (2000). Metodologi Penelitian Kualitatif. Bandung: Remaja Rosdakarya.

Natale, S. (2012). Photography and Communication Media in the Nineteeth Century. London: Loudborough University.

Pemkab Ponorogo. (1993). Pedoman Dasar Kesenian Reyog Ponorogo dalam Pentas Budaya Bangsa. Ponorogo: Pemkab Ponorogo.
Purwasito,A.(2015). Komunikasi Multikultural. Yogyakarta: Pustaka Pelajar.

Samovar, L., Porter, R., R.Mc Daniel, E., \& Roy, C. (2013). Communication Between Cultures. Eighth Edition. Wadsworth: Cengage Learning.

Saville-Troike, M. (2003). The Ethnography of Communication.An Introduction. Third Edition. Oxford: Blackwell Publishng Ltd.

Simatupang, L. (2013). Pergelaran: Sebuah Mozaik Penelitian Seni Budaya. Yogyakarta: JalaSutra.

Smith, K., Moriarty, s., Barbatsis, G., \& Kenney, K. (2005). Handbook of Visual Communication Theory, Method, and Media. London: Lawrence Erlbaum Associates Publisher.

Soedjono, S. (2006). Pot Pourri Photography. Jakarta: Universitas Trisakti.

Sontag, S. (2005). On Photography. New York: Rosseta Book.

Tannen, D. (1994). Talking from 9 to 5. New York: William Morrow and Company, Inc.

The History of Visual Communication. (2016, 2 20). Diambil kembali dari the history of visual communication: http://www. citrinitas.com/history_of_viscom/

Williams, R. (1983). Writing in Society. London: Verso. 